This preprint copy is an accepted manuscript of the chapter published in Intersections of Formal and Informal Science in 2016.

Please cite as:

Dawson. E. (2016). When Science is Someone Else's World. Pp. 82-92 in L. Avraamidou \& W.-M. Roth (Eds.), Intersections of formal and informal science. Routledge: London and New York

[NumWords: 5042]

To appear in L. Avraamidou \& W.-M. Roth (Eds.), Intersections of formal and informal science. New York, NY: Routledge.

\title{
When Science is Someone Else's World
}

Emily Dawson

\section{University College London}

It is quite confusing I think, I don't know, I like the idea of liking the [science] things, but actually to do them is something else. So I like the sense of going to the zoo, purely just to see the animals, but I wouldn't. I don't like touching them. I don't like being in that kind of environment. So I think it's all about fascination. So you said I like how things are built and how things are, so seeing an animal in a cage, it gets my brain thinking, oh the journey that the animal had, like to get a lion from the jungle, to get it to the zoo, the cage, and see how the lion actually adapts, 'cos it's a different scenario for the lion. So things like that are interesting for me, but the thought of touching animals, it's not my cup of tea, in terms of the museums and stuff like that, I, it's not my cup of tea at all (laughs) 
How does it feel when ISE isn't your “cup of tea"? I first met Fatima in February 2010 while exploring social exclusion from public science and ISE. There are two key things you should know about Fatima for this chapter; first, she loved particular aspects of science, and second, despite her support for the study, Fatima was an unwavering critic of ISE.

As a former ISE practitioner, I knew it was as easy as looking across a crowded gallery to know ISE was not very inclusive. Surprisingly, at that time little research was available about how exclusion from public science worked, let alone how ISE could become more inclusive. My colleagues and I found that job titles like “Community Officer" and "Diversity Manager" were sometimes used by our institutions to partition equity issues off from day-to-day work, often against the best intentions of those involved. As Ahmed (2010) notes in her study of diversity workers in higher education, institutional practices can limit such roles; creating inclusive job titles can give the appearance of inclusion, while making little structural change. Faced with these mounting frustrations I set out to explore ISE from a different perspective, that of a non-visitor.

In this chapter I draw on data from what became an ethnographic study carried out with four grass-roots community groups in London to explore how they engaged (or not) with science in their lives. Over two years I worked with a Sierra Leonean group, a Somali group, a Latin American group and an Asian group, attending group meetings (dances, festivals, celebrations, picnics and ISE visits), where I carried out interviews, focus groups and observations. The groups were approached on the basis of data that showed ISE participation in the UK was marked by race/ethnicity and 
class (Dawson, 2014a). All participants therefore came from low income, minority ethnic backgrounds, but a range of different ages.

I begin this chapter by outlining why it is important to consider public science through the lens of equity and the theoretical tools I use to do so. I then briefly describe attitudes and experiences of science across all four groups, followed by a more detailed account from one person, Fatima. In looking at Fatima's stories and experiences I hope to illustrate that being interested in science does necessarily pave the way to participation in public science activities such as ISE. I argue that exclusion from public science is not a question of rebranding and changing perceptions, but instead goes to the core of how ISE is understood and practiced.

\section{Why does Inclusion in Science Matter?}

Where, how, with whom, how much and why we engage with science (or not) matters. I frame group and individual experiences of science, ISE and ISL against the social reproduction of disadvantage because it is against that backdrop that questions of inclusion and exclusion are important. If science were irrelevant, it would not matter who spent their time amongst its institutional norms and texts, absorbing the language, shaping the appropriate ways of being or imagining themselves in future science stories. Science is a prized resource in our societies. It is therefore important to map where people encounter science in their lives and what happens when they do.

Public science takes many forms, from the overtly political to activities designed purely for fun. In this chapter I focus on science in general as well as science learning in designed, institutional spaces (ISE) -museums, science centres, zoos or science festivals and more - and the harder to map informal science learning (ISL) that happens everyday. The ever-growing field of ISE institutions is potentially a useful space for people to engage with science, to imagine themselves within the 
world of science and to try out being science insiders. Alongside these institutionally structured practices are millions of more nebulous science encounters in the wild (ISL); reading science stories in newspapers, following science stars like Neil deGrasse Tyson on twitter, watching science on television (from The Big Bang Theory sitcom to the Planet Earth documentaries), or chatting about science amongst friends and families. I focus on both ISE and ISL here because they infiltrate people's lives in different ways.

Does this wide and varied field of public science practice create multiple, equitable pathways around, through or into science for everyone? Unfortunately not. For example, ISE practices appear to be exclusive, marked by social structures such as ethnicity, class, gender and other social positions (Dawson, 2014a, 2014b). This means that exclusion from ISE is hierarchical (because it reflects patterns of social disadvantage) and intersectional, (because those disadvantages overlap). But perhaps we should not be surprised that public science activities are exclusive since school science is also patterned by privilege. Research in science education has shown that some people get turned off science at school while others are supported to pursue science studies and careers (Brown et al., 2015; Lemke, 1990). What then might it look like if this vast array of ISE, ISL and formal science learning opportunities were not for you? How might it feel to be excluded?

\section{Theoretical Background}

To understand how a sense of being excluded from science might develop and be reproduced I draw on concepts from research on social reproduction and exclusion. In doing so I stray into the dubious territory of describing people as excluded, what Becker called "the act of labeling, as carried out by moral entrepreneurs" (1963, p. 179). It is important therefore to note that research is as guilty of reifying social 
divisions as any other practice. I explore how people and power come together in potentially damaging practices, with a view to describing and changing that system.

I use Bourdieu and Passeron's (1990) work on symbolic violence to think about the relationships between a specific field (public science, ISE, ISL), the forms of capital valued by that field and the disposition towards the field, or habitus, of those involved. Symbolic violence is the misrecognition of power and agency, such that the disenfranchised - the working class for Bourdieu and Passeron - make a virtue of necessity by interpreting inaccessible opportunities as choices not to participate. In other words, symbolic violence is present when exclusion from a given field of practice or set of institutions feels like something so anticipated by your ways of thinking that you might never expect to be included, that your exclusion feels natural and, sometimes, desirable.

Imagine for a second the un-thought assumptions that guide your day-to-day life. I, for example, automatically walk into female, not male public toilets, I sit upstairs but not at the back of London buses and I avoid unlit parks at night. All these embodied practices emerge at the junction of who I am and how I understand my places and roles in the society I live in. From this perspective, not using ISE or disliking science could become an embodied disposition, a way of being, developed across groups whose experiences are similar, what Bourdieu called habitus (1998).

Institutions are renowned mechanisms of social reproduction. As such, we need to pay attention to questions of belonging, who feels welcome and unwelcome in science, ISE and ISL, what Ahmed describes as "how some more than others will be at home in institutions that assume certain bodies as their norm" $(2012, \mathrm{p}$. 3). Thus, drawing on Ahmed (2010) and Becker (1963) I use the device of insider/outsider in this chapter as a way to think through what might be involved in participants' 
experiences of science and how they position themselves in relation to science, ISE and ISL as a result.

I locate insider/outsider positions within participant's identity practices, drawing on the work of Holland, Skinner, Lachiotte and Cain (2001) to frame identity practices as fluid, reimagined or reinforced in specific contexts and rooted in relationships with others, though enacted by individuals. In contrast to Bourdieu's notion of collective dispositions, or habitus (1998), the notion of identity in practice helps me to think through the differences between people, as well as where they may be similar. Unfolding identity practices at an individual level therefore means looking at how ways of being, learning and becoming are traced through with historic, social and political features, but remain open to change and agency. In this crucial sense Holland et al. (2001) leave agency foregrounded in their understanding of people's actions in ways that Bourdieusian work is less attuned to (Bourdieu, 1998; Bourdieu \& Passeron, 1990). While it is vital to unfold how power and exclusion operated in science and ISE, so too must room be left for people to genuinely reject participation in ISE, even if at the same time the conditions are such that they would be excluded anyway.

\section{Science as Inaccessible and Unappealing}

\section{On Being Disposed Against Science}

"Science...it's a subject very far from my reality, from what I do" stated Alejandro from the Latin American group. Like other participants, science was something Alejandro felt he had no control over, no stake in and could not imagine a scenario where he might be more involved in science, whether politically, culturally, socially or educationally framed. Across the four community groups participants described an overwhelming disassociation from science, at school, ISL and ISE 
settings, jobs or an any other aspects of their lives where the thought they might encounter science.

This sense of alienation, of being outside or tangential to science and public science, was particularly acute when it came to ISE. With few exceptions, science museums and centres were unfamiliar to participants and those visited as part of the study highlighted how exclusion was embedded in ISE practices such that the visits confirmed their pre-existing views of ISE as problematic and exclusive (Dawson, 2014b). Where participants did have experiences of ISE to reflect upon, such spaces were described as whitewashed and Eurocentric, expensive, irrelevant to their lives and communities and, as a result, worth avoiding.

Participants saw ISE institutions as unwelcoming, hostile places, where they did not belong, drawing on their perceptions of institutional whiteness and their sense of being outside ISE and outside science. Being outside exists only in relation to the possibility that someone is inside (Becker, 1963). We should recognize therefore, as Ahmed (2010) reminds us, that the problem of exclusion is not that of perceptions of institutional whiteness but of institutional whiteness itself - ISE practitioners and users in the UK are drawn overwhelmingly from the White ethnic majority (Dawson, 2014a).

In contrast to ISE, participants in all groups remarked on ISL encounters, particularly watching science on television (from detective shows to comedies). Such programmes were however, not framed by participants as supportive of an orientation towards science or of being science insiders, for all that they were perceived as more accessible. Watched for entertainment value, science on television featured an all-star cast of people who were "not like us." As Kirin from the Asian group put it when talking about the television series CSI (Crime Scene Investigation), "we're very 
interested but you know, we can't push ourselves forward." For her, her friends and participants from other groups, science on television was represented by people who were special, impossibly clever, but not like them and did things they could not do, echoing the idea found repeatedly in science education that science was difficult and the reserve of the "genius" few (Lemke, 1990). In the same breath therefore as participants named a series of famous white male science presenters, including Sir David Attenborough, Steve Irwin and Sir Patrick Moore, they highlighted the social distance between themselves and their perception of who were involved with science.

Across all four groups science was perceived as a difficult and unpleasant subject to study, of little relevance, little interest and little use to participants or their communities. As Maria, a mother of four from the Latin American group explained, "the way science is presented at school is very boring and uninspiring." Concerns about employability and income influenced many participants views on whether pursuing an interest in science was worthwhile. Formal science education appeared especially irrelevant because pursuing a scientific job was seen as impossibly hard, backed up by stories of friends and family who had tried and failed to work in the sciences. In each community group participants (with three exceptions, one of whom was Fatima) talked about how they had stopped studying science as soon as they could, with some specifically noting school as the key factor that had put them off science.

The collective sense of disassociation from science and ISE across the four groups is striking in terms of habitus and symbolic violence (Bourdieu, 1998; Bourdieu \& Passeron, 1990). Science was a difficult subject, off-putting at school and of little value for work, while ISE appeared invisible, pointless, and exclusive or, in the case of ISL and television, entertaining but not something they could identify 
with. Science was understood to be marked by 'race'/ethnicity, class, gender and, in some cases, age, in ways that did not welcome participants.

As a result, participants steered clear of public science activities, withdrawing from a system they interpreted as disadvantageous and arranged against their interests. They were disposed against science and public science. As Bourdieu and Passeron (1990) argue, the most effective form of domination is that which "comes from exclusion, which perhaps has the most symbolic force when it assumes the guise of self-exclusion" (pp.41-42). Participants saw themselves as science outsiders and behaved accordingly. For participants science was historically, socially and culturally constructed as a world for people who were, as Mirza from the Asian group concluded, "not like us." In this sense their involvement was framed as hard to imagine, unwanted, unthinkable and unlikely.

\section{Fatima: When an Interest in Science is not Enough}

When I met Fatima she was in her mid 20s and been involved with the Somali community group for several years. She became a key participant from that group; supporting the research as a gatekeeper and general explainer who unpicked the nuances I missed, translating (literally and conceptually) between other members of the community group and me. Exploring Fatima's experiences and attitudes is interesting because amongst the 60 people who participated in this study, she and two others were the only ones who expressed personally liking science and had tried to study it further, albeit without success. I discuss Fatima's stories, reflections and experiences here to show how some of the themes briefly sketched above appeared in the context of someone's life.

Fatima had grown up in the UK, going through the British school system and to a post-16 college, though not to university. She lived at home with her extended 
family of siblings, their spouses, their children and her mother. Fatima described herself as the "odd one out of the family, I'm a weirdo" because she was interested in science and preferred staying in reading books to going out, but agreed that "none of us really like museums." In talking passionately about science one day she said "I've got a fascination with Biology, how the body functions and how each part of the body has a function." In turned out that the kinds of books Fatima read were also unusual from her perspective compared to what her friends and family enjoyed reading; Fatima read science books - specifically books on engineering and biology. It seems safe to say that Fatima really liked science.

Not only was Fatima into science and reading books about it, she pursued her interests in science through other forms of ISL, seeking out ways to develop her self in relation to science purposefully through specific practices. For instance, she talked about going online to research her scientific interests and being known amongst family and friends as good at finding useful scientific information when it was needed. Unlike other participants, she chose to watch television programmes with a lot of science content. For instance, in the extract below, she describes a nature documentary she had enjoyed:

I'm fascinated just to look at an animal and then to see how the animal came about, 'cos like, I was watching a documentary the other day and like, um, small animals like birds when they were tiny, they were showing how they develop, and how in a couple of months they get bigger and bigger and you have the big pigeon that you have.

Fatima's presentation of herself and the views held of her by others that she echoed were at least partially built around her orientation towards science, her skill with 
scientific information and her seemingly well-known liking of science. In other words, science featured in her "practiced identity" (Holland et al. 2001, p. 271).

Being disposed towards science was, for Fatima, not as straightforward as a habitus that endowed her with a "feel for the game" of science and public science (Bourdieu, 1998, p. 25). It was with some discomfort, some residual sense of outsider status that Fatima positioned herself as different to her family and friends through her unusual or "weird" interests in science and her choice of ISL activities, as though she was misaligned with the collective habitus, the collective disposition against science within her community. In this sense Fatima saw science, scientists and those with science interests like herself as unlike other people, echoing the statements of other participants and other studies about scientists as "geniuses" (Lemke, 1990).

In conversation with her friend Idyl, another Somali participant in her midtwenties, Fatima described scientists as different, agreeing that they were not "normal" people like her friends. In these conversations scientists appeared compelled to further science, no matter what the social or ethical costs, morally dubious and alarmingly clever, outside the social norms and behaviours she expected (Becker, 1963). Fatima struggled therefore to negotiate her disposition towards science, or habitus, using ways of talking, behaving and other identity practices to bridge perceived social distances and deviant behaviours between herself, her community, science and scientists (Becker, 1963; Holland et al, 2001). Thus, in how she presented stories of herself in relation to science writ large, Fatima worked to balance a self that was both science insider and outsider, both "weird" and "normal".

\section{On "Hating" ISE}

In one of our first meetings Fatima bluntly told me: "I hate museums." In a later interview she continued: "I'm very upset with the museums, so I'm not going...I 
just did it because I had to do it at school, but now it's not part of my social outlook, why do something you don't, it's not part of you." Compared to her presentation of self in relation to science in general terms, Fatima saw herself as definitively outside ISE, but also, crucially, that ISE was outside and irrelevant to her life and her friends, as she said, "not part of you." Fatima's experiences of and attitudes towards ISE were in line with those of the other participants. That is to say, with a collective habitus or disposition that oriented them away from ISE as by and large unheard of, unusual, unhelpful at best and damaging at worst (Bourdieu, 1998).

Unlike most of the other people involved in the project, Fatima was able to draw on her previous experiences of ISE at length because she had visited several museums and similar institutions, including the Natural History Museum, the British Museum, the Science Museum, London Zoo and Vauxhall City Farm. But these visits did not mean Fatima liked ISE. On the contrary, she told me she thought ISE outreach practices failed to meet those they should (all of the public) and were simply not up to standard. She said she had never seen an advert for an ISE institution in her neighborhood, nor leaflets, signs, or information in community newspapers, websites or on radio stations and that she felt her community had been left to one side as a result.

Fatima's views of ISE institutions had been influenced by her experiences while at school. In fact, all but one of Fatima's ISE experiences (Vauxhall City Farm) had been via a school trip. Fatima described school ISE visits in negative terms as "a sort of detention" and "punishment." These experiences were strongly framed by what Holland et al. (2001, p. 271) call a "figured world" within and against which peoples identities develop, in this case, the figured world of compulsory schooling. 
It wasn't enjoyable, any museum that you went to as a kid, it's not really what you would say is the best time that you had in school, like it was like a punishment, they would say that you're going on a trip, and then you turn up at the Natural History Museum or the Science Museum or something like that, and it's not really a trip that a child imagines, you know, the night before, packing it's pack lunch, you don't really imagine that you'll be in a tour with a tour guide that doesn't really care because it's been doing it all day and you're the last group, and it's like whistling through the whole museum, so, in terms of that, no I wouldn't, I wouldn't imagine putting myself in that.

In the extract above, Fatima contrasts childish delight at the idea of a day away from school with the disappointing realization that ISE mimicked the figured world of school, complete with teachers, bored guides and rules to follow. ISE visits were motivated from Fatima's perspective by her teachers' seemingly incomprehensible love of ISE spaces, with largely undelivered potential for learning science and having fun. So much so, that once ISE visiting was no longer mandatory, Fatima had tried never to visit them again.

Fatima's underlying assumption was that participation in ISE or anything like it would be unusual for her, her friends, family and broader community. As she put it, “I don't know anyone that's decided one day 'oh, let's go to the museum'." Her experiences generated a story about ISE as poor-quality, off-putting and irrelevant, a story reinforced and reproduced socially amongst her community and friends, into a world where science and ISE was inaccessible, unpleasant and removed from day-today life. 
Despite her personal interest in science therefore, visiting an ISE institution was not a choice Fatima expected to make, nor did she expect her friends or family to do so, as the extract below shows:

Fatima: if you don't know anything about the museum and it's not part of your social outlook then you don't know what's happening in the museum

Emily: Yeah, and you'd never look it up?

Fatima: You'd never look it up, you wouldn't have no need to because it's not something you do.

This extract speaks to a deeply ingrained sense of not belonging in ISE, but also echoes how Fatima made sense of her alienation from ISE; she was an ISE outsider, but ISE was in turn outside her life and her community.

Fatima's stories about science and ISE provide a useful account of the complexity of people's lives and a concrete context for exclusion from science, ISE and ISL. Fatima shared the collective disposition against ISE with other participants, but unlike others, was disposed towards science and certain ISL practices. She worked hard to find ways to understand what at times felt like contradictory dispositions. Holland et al. (2001) have suggested that people frequently face situations of contradiction, where one or more aspects of their positional identities conflicts with another aspect. Similarly, Roth (2008) has argued that engaging with science from a marginalized social position creates cross-cultural differences that require considerable negotiation and produce multiple, heterogeneous identities. As Fatima said in the quote that opened this chapter "it is quite confusing" to both like science and dislike certain kinds of science engagement opportunities. 
Fatima's descriptions of the irrelevance of ISE to her life and her confusing social distance from science can be interpreted as an articulation of her experiences of marginalization and as a way to resist such experiences. Through constructing positions from which to criticize ISE practices, Fatima was able to acknowledge the ways in which she was excluded from such practices whilst simultaneously rejecting those practices on her own terms. Fatima did not like science because of her ISE experiences, but rather, in spite of them.

Understanding how Fatima made sense of her views and experiences of science through contradiction, confusion, being a science insider but an ISE outsider suggest that agency and identity work play a key role in negotiating between individuals, fields and collective habitus. As Ogbu (1992) has argued disidentification with educational institutions can be considered a form of agency. Drawing on Holland et al. (2001), I suggest in addition to being structurally excluded, through their behaviours and speech participants actively spurned science and public science. Thus, while people's individual positions towards different aspects of public science varied - Fatima rejected ISE while other participants disidentified with public science activities and science altogether - they were not wholly passive in their exclusion.

In this sense agentic rejection and structural exclusion go hand in hand to reproduce social disadvantage, with both sides of the coin in play exclusion/rejection becomes a resilient system, hard to change and rooted in symbolic violence (Bourdieu \& Passeron, 1990). Symbolic violence then is "based on 'collective expectations' or socially inculcated beliefs" (Bourdieu, 1998, p. 103). It sneaks into well-meant intentions, in doing what you have to do, usually do and expect to do. As Fatima put it, "why do something you don't, it's not part of you." 


\section{Conclusions}

This study taught me that exclusion and rejection are habits of mind, embodied practices, assumptions and expectations that work together. Participants' disassociation from science in general and ISE in particular, made their exclusion all the more resilient. That participants' expectations of being ISE outsiders were met in practice by those who visited museums and science centres as part of the study was even more appalling (Dawson, 2014b). Their exclusion was embedded in the ISE practices they encountered, written into exhibit texts and mirrored in photographs. The ISEs participants visited were whitewashed, not only terms of the other people there, but in content and representation; people who looked like them were either invisible or the subjects of science, stars of exhibits about evolution or disease, but rarely (if ever) the revered scientists themselves. The pernicious combination of people being disposed against science and ISE, rejecting a system that disadvantaged them and their structural, institutionalized exclusion created a world where participation in science activities was marked by privilege in ways that were durable.

The resilience of the assumption that science and ISE are for some but not for others is the hallmark of symbolic violence and the reproduction of disadvantage. If we are going to take the seriously the challenge of making science inclusive, we have to disrupt these expectations and beliefs at their roots. Fatima's stories show that we must unsettle the idea that people do not participate in ISE because they do not like science, or do not know enough about science, or ISE.

As I have argued elsewhere, an assimilationist tendency informs a great deal of public science, springing from the belief that public science practices are inherently worthy and exclusion arises as the result of barriers to access (Dawson, 2014c). What I hope to have shown here is that social exclusion from public science is more 
complex, more intersectional and more embedded than it might first appear, that only significant changes on the parts of practitioners, policy makers and researchers can change core practices and patterns of exclusion. We must therefore develop forms of research and practice that seek to disrupt rather than reproduce these patterns of privilege and disadvantage in relation to science. If public science activities, ISE or ISL are worth anything to our societies, then they must be inclusive.

\section{References}

Ahmed, S. (2012). On being included: racism and diversity in institutional life. Durham and London: Duke University Press.

Bourdieu, P. (1998). Practical reason. Cambridge: Polity Press.

Bourdieu, P., \& Passeron, J.-C. (1990). Reproduction in education, society and culture (R. Nice, Trans. Second ed.). London, Newbury Park CA, New Delhi: Sage.

Brown, B., A., Henderson, J. B., Gray, S., Donovan, B., Sullivan, S., Patterson, A., \& Waggstaff, W. (2015). From description to explanation: An empirical exploration of the African-American pipeline problem in STEM. Journal of Research in Science Teaching, Advance online publication, Early View.

Dawson, E. (2014a). Equity in informal science education: developing an access and equity framework for science museums and science centres. Studies in Science Education, 50(2), 209-247.

Dawson, E. (2014b). "Not Designed for Us": How Science Museums and Science Centers Socially Exclude Low-Income, Minority Ethnic Groups. Science Education, 98(6), 981-1008. 
Dawson, E. (2014c). Reframing social exclusion from science communication: Moving away from 'barriers' towards a more complex perspective. Journal of Science Communication, 13(2), 1-5.

Holland, D., Skinner, D., Lachiotte Jr, W., \& Cain, C. (2001). Identity and agency in cultural worlds. Cambridge, MA and London: Harvard University Press.

Lemke, J. L. (1990). Talking science: Language, learning, and values. Westport: Ablex Pub. Corp.

Roth, W.-M. (2008). Bricolage, métissage, hybridity, heterogeneity, diaspora: Concepts for thinking science education in the 21 st century. Cultural Studies of Science Education, 3(4), 891-916. 